\title{
CANTO E Música LitúRgica
}

como cultivar uma espiritualidade unificadora em meio aos desafios da pandemia?

\author{
Ms. Eurivaldo S. Ferreira* \\ Frei Telles Ramon, O. de $M^{\star \star}$
}

DOI: https://doi.org/10.52451/teopraxis.v37i129.14

Recebido: 03 de março de 2019 | Aprovado: 09 de junho de 2019

Resumo: Em meio à pandemia aumentaram os mecanismos de transmissão para as celebrações paroquiais e diocesanas. A porção do povo de Deus saiu do caráter territorial jurídico caracterizado pela Igreja Particular e passou para o além-fronteiras da realidade cibernética. Os elementos simbólicorituais da celebração litúrgica deixam de ter sua relação de proximidade devido ao distanciamento social. As assembleias, sem poderem participar ativamente dos ritos através dos sentidos ficaram privadas do paladar, do olfato, do olhar, do escutar e do tato, percepções reais que aguçam à participação em tempos normais. As chamadas telas dos aparelhos eletrônicos dividem o olhar com outros aplicativos seja de chamadas, entretenimento e informação ou comerciais. Em meio a tudo isso, como garantir que os elementos simbólico-rituais cumpram sua função significativa de agregar às liturgias seu poder revelador mistérico? Como desvelar o segredo dos ritos por meio das telas sem a participação ativa das assembleias? A música litúrgica se coloca como um desses elementos altamente simbólicos e

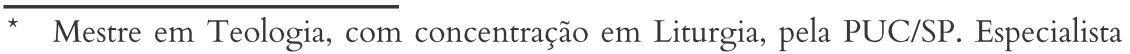
em Liturgia pelo IFITEG-GO. Graduado em Teologia pela PUC/SP. Músico. Membro da Rede Celebra de Animação Litúrgica. Membro do Corpo Eclesial de Compositores da CNBB. Membro do Universa Laus. Agente da Pastoral Litúrgica na Paróquia Santo Antônio do Bairro do Limão, Arquidiocese de São Paulo.Email: euriferreira@gmail.com

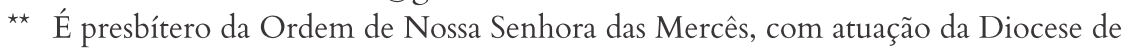
Santo André/SP. Membro do Corpo Eclesial de Compositores da CNBB. É redator do Subsídio litúrgico-catequético da CNBB “Igreja em Oração". Produziu as gravações dos álbuns: Hino da CF 2018, CF 2019 e CF 2020 e Cantos quaresmais. Pela Ed. Paulus gravou os seguintes álbuns: "Chamaste-me, Senhor", "Cristo, Clarão do Pai”, "O Mistério em Canto", "Povo de Deus, povo sacerdotal” e “Ao Coração de Cristo”. Email: freitellesramon@msn.com 
reveladores dos mistérios da fé. Ela ajuda a comunidade a vivenciar as ações rituais, sendo o próprio rito ou acompanhando as ações rituais. Nesse nosso artigo fazemos alguns questionamentos sobre a produção, a execução e os embates do campo musical que trouxeram a pandemia e as celebrações virtuais. Como nenhum setor estava preparado para isso, a intenção não é apontar autorias ou até mesmo provocar a polêmica, mas sim elucidar e retomar alguns pontos conquistados após o Concílio Vaticano II e que podem ser revistos e colocados em prática à medida em que o que está em jogo é a participação ativa, plena, consciente, frutuosa, interna e externa do povo de Deus através das celebrações litúrgicas.

Palavras-chave: Liturgia. Música litúrgica. Assembleias. Espiritualidade. Pandemia.

\section{Introdução}

A liturgia entendida e vivida como fonte de espiritualidade foi uma das grandes e preciosas redescobertas do Concílio Vaticano II. A Constituição Conciliar Sacrosanctum Concilium (SC) nos recorda a identidade original da Sagrada Liturgia: "Ela é a primeira e necessária fonte onde os fiéis hão de beber o espírito genuinamente cristão" (SC 14).

Ao participarmos da liturgia, nos é dada a oportunidade de aderir e interiorizar o jeito de ser de Jesus Cristo que, pela ação do Espírito Santo, forma em nós um homem novo, uma mulher nova, pela força pascal de Jesus e nos transforma integralmente, seja na nossa realidade pessoal e social.

Com essa "evolução" e redescoberta, ou seja, volta às origens, a liturgia deixa de lado aquele arcabouço rígido e pesado que decorre de uma compreensão ritualística e formal e passa para uma assimilação e experiência vital da liturgia como caminho mistagógico - uma porta de entrada eficaz para se adentrar no Mistério de Cristo, o qual realiza no ser humano a transformação pascal, que nos faz encontrar nossa real identidade em Cristo.

Dentre as ações rituais, sinais sensíveis, palavras e gestos, 
destacamos a força do canto e da música na liturgia. A música litúrgica é aquela que, com sua letra (poesia) e melodia, cumpre o papel de ser parte integrante da ação litúrgica, ou sendo o próprio rito, ou acompanhando a ação ritual. Além disso, o canto e a música litúrgica devem ser a expressão da fé de uma comunidade, pois se trata de viver a experiência de se entrar no mistério pascal quando se canta.

\section{Da música de igreja à música litúrgica}

Reconhece-se uma música litúrgica por sua natureza ritual. Não basta apenas que o texto diga palavras religiosas ou de cunho sagrado. A esta música nós chamamos de 'música religiosa', mas não está apta para servir a liturgia. Recorremos, então, à história para podermos identificar a evolução da música que adentrou aos templos até chegarmos no conceito da música que habitualmente empregamos hoje.

A partir de estudos acadêmicos é possível verificar e aprofundar a classificação da música que serviu aos cultos litúrgicos durante um período considerável da história da Igreja. E com a reforma protestante (séc. XVI) todos os cantos passariam então a ser chamados de 'música de Igreja'. Tratava-se então de compreender que se falava da música destinada ao culto, mas com uma percepção bem limitada, o que excluía, por sua vez, a música herdada das comunidades judaico-cristãs, por exemplo.

Já a música sacra, denominação mais comum para a música das igrejas cristãs, além de simbolizar uma característica de música, foi a que mais concorreu para o serviço litúrgico. Trata-se de uma música que foi composta para servir a liturgia com adaptações ou adequações que, por sua natureza, teve origem na música erudita. Mas a mesma música sacra que servia às ações litúrgicas era também objeto de comemorações públicas ou privadas, externas às ações rituais cristãs, apreciadas até hoje em teatros, concertos e outras ocasiões. 
É a partir do Concílio Vaticano II que entre os católicos se adota o termo 'música pastoral', com o intuito de identificar a música aliada à função pastoral das comunidades locais. A intenção é que esta música seja um ponto de ligação entre as diversas atividades da Igreja e sua diaconia. Mas 'pastoral' também é um termo geral, o que não especifica muito a linguagem musical que se deseja para a música ritual.

Como alternativa à música pastoral estudos pós-conciliares adotaram a expressão 'música ritual' para a música propriamente que se relaciona com os ritos e as ações litúrgicas. Um grupo internacional de estudos ligados à música da Igreja pósconciliar chamado Universa Laus designa esta música como sendo uma 'música ritual cristã', pois denomina o que se faz nos ritos, já que a eles está ligada.

Um termo também bastante ocorrente é 'música litúrgica' ou 'música ritual', o que possibilita alargar a compreensão por tratar da música de culto da tradição judaico-cristã. Esta música tem ênfase no rito, nas palavras, nas ações, no espaço físico e na melodia em si. Portanto, é um termo mais adequado e apropriado para a música do culto cristão. É a partir dessa terminologia que ampliamos nossa discussão.

É bom também lembrar que todas as religiões possuem músicas que estão ligadas às suas ações rituais e que diferem da música de outros ambientes não religiosos. Mas a música ritual não é propriedade apenas das religiões. Os povos indígenas, por exemplo, possuem um repertório imenso de música ritual, e essas músicas nem sempre estão ligadas às formas de celebrações religiosas, mas sim ao contexto cultural e do ambiente em que vivem. São conhecidas do folclore brasileiro as músicas que acompanham festejos populares, como músicas de chegada, de partida, de velórios, de comemorações, de danças de rua, de brincadeira e diversão etc. Esse repertório foi pouco a pouco se inserindo na musicalidade do povo brasileiro, chegando até mesmo a fazer parte da música popular brasileira. 


\section{A música litúrgica possui propriedade e fins específicos}

Digamos que é de suma importância que todos os que estão envolvidos com a música litúrgica nas dioceses, paróquias e comunidades cristãs tenham consciência, antes de tudo, da compreensão da natureza funcional e da característica ritual da música litúrgica. Daí nasce o entendimento de que a criação de novas composições não é um assunto encerrado, mas sim, que exige estudo, aperfeiçoamento e aprofundamento em algumas áreas de competência e que ajudam em muito a formar especialistas e compositores nesta área.

O Estudo 79 da CNBB: A música litúrgica no Brasil vai afirmar que "é isso que, em cada caso, definirá as escolhas a serem feitas em termos de texto, melodias, ritmos, arranjos, harmonias, estilos de interpretação etc. $\mathrm{O}$ importante é que determinada criação musical sirva para a comunidade celebrante desempenhar bem o rito que realiza" (n.197). E ainda continua dizendo que "esta funcionalidade da música litúrgica, ao delimitá-la com precisão, em nada vem a prejudicar sua qualidade como arte musical, nem bloquear a inspiração do artista litúrgico" (n.198). Por isso, ao falarmos de produção de novas músicas litúrgicas, devemos levar em consideração os aspectos acima, pois são alertas positivos já assegurados pelos bispos que reuniram numa obra os estudos técnicos sobre a música litúrgica. Passamos então a tratar de conteúdos específicos para as letras dos cantos que cantamos em nossas celebrações.

Isso significa dizer que a Igreja não se fechou à criação de novas composições, mas que se faça com clareza o incremento de repertório significativo para se preencher eventuais lacunas. Não se trata de compor por compor. O compositor, outro importante ministério na vida da Igreja, é aquele sujeito que, com a arte das palavras, da poesia, da música e da harmonia, oferecerá à comunidade de fé uma música litúrgica feita de textos enriquecidos com uma tal beleza, "cujo valor, verdade e 
graça não são medidos apenas pela sua capacidade de suscitar a participação ativa, nem (só) por seu valor estético-cultural, mas (principalmente) pelo fato de permitir aos que creem implorar os 'Kyrie eleison' dos oprimidos, cantar os 'Aleluias' dos ressuscitados, sustentar os 'Maranatha' dos fiéis na esperança do Reino que vem” (Universa Laus).

Quanto às músicas tradicionais, aquelas que atravessam gerações, é importante lembrar da importância de determinada música em tempos específicos de nosso cotidiano. Não se canta "Noite feliz' no mês de fevereiro, por exemplo; as marchinhas de carnaval são mais próprias do período de carnaval; assim como as músicas caipiras retomam com sua força própria nos festejos juninos; um grupo de soldados desfila ao som dos dobrados; muitas músicas populares nasceram em meio a manifestações sócio-políticas no conjunto da nossa construção democrática. Portanto, podemos falar de um tesouro audível que guardamos e que, de tempos em tempos, nós o resgatamos para servir a esta ou àquela situação.

Da mesma forma é o canto tradicional religioso ou litúrgico que perdura por tempos na Igreja. Este nunca deixará de ter sua função para a comunidade de fé. O que seriam nossas 'sextasfeiras santas' sem o 'Vitória, tu reinarás'? Esses cantos ressurgem com certa força e vibração em tempos fortes da Igreja, por isso pertencem ao que chamamos de 'reserva simbólica', já que retornam em certas ocasiões e nos trazem a memória de um tempo litúrgico ou uma comemoração específica pelos quais alimentamos nossa fé.

\section{Desafios e critérios para a música litúrgica}

Contudo, carece-nos esclarecer, e aqui chegamos ao ponto central de nossa reflexão, quais são os desafios que nos colocaram esse período de pandemia para a música litúrgica, para os ministros que ocupam esse papel nas celebrações e para 
a Igreja em geral. Antes de tudo, recordemos os critérios básicos que direcionam para que o canto e a música estejam ligados à ação litúrgica: a beleza expressiva da oração, a participação unânime da assembleia nos momentos adequados e o caráter solene da celebração.

Em sua Revista de Liturgia escreveu Ir. Penha Carpanedo que

O ícone mais representativo da participação litúrgica requerida pela reforma do Concílio Vaticano II é uma assembleia 'cantando a uma só voz'. É quando a fé de uma comunidade reunida se expressa em 'sinais' como o canto e a música, alguns dos quais mais 'sensíveis' de nossa cultura, especialmente quando enriquecidos com nossos ritmos e com nosso gingado ${ }^{1}$.

\section{Ademais, acrescentamos que}

A música não é um acessório na liturgia, mas é parte integrante do rito. Com seu significado visa suscitar na assembleia uma atitude de fé que brota do coração, seja no simples canto 'a capella', seja quando produzida ou acompanhada pelo som dos instrumentos, incluindo os de percussão. Desse conceito podemos extrair ótimos resultados quando o que está em jogo é a grande influência que exercem o canto e a música na vida de muitas comunidades ${ }^{2}$.

Ao reforçarmos os três critérios básicos elencados acima, superamos, por exemplo, aquelas músicas que se veiculam com certas marcas da subjetividade, do devocional de caráter 'estilizado', do sentimentalismo, pois essas estão distantes da objetividade da fé. A música é parte integrante da ação litúrgica (cf. SC 112), tem caráter teológico, está a serviço da letra no seu contexto ritual [canto de abertura, por exemplo, tem a ver com ritos iniciais e o tempo litúrgico, canto de comunhão tem a ver com o evangelho do dia e o tempo litúrgico].

1 Penha CARPANEDO, In: Revista de Liturgia - cantando a uma só voz, n.251, p.3.

2 Penha CARPANEDO, In: Revista de Liturgia - cantando a uma só voz, n.251, p.3. 
A função da melodia aliada aos instrumentos musicais é reforçar o sentido da letra. Quando se canta as chamadas Partes Fixas da missa, o texto presente no Missal Romano deve prevalecer sem alterações e acréscimos desnecessários. Esse conjunto de textos próprios da missa requer melodias simples e objetivas, que enfatizem o que diz a letra.

\section{Quem canta? Como se canta a música litúrgica?}

Quanto à forma de cantar, o canto litúrgico não pode reproduzir o estilo dos programas de auditório. Não se trata de um show em que os atores projetam sua voz e fazem sua performance; trata-se de uma assembleia em oração, e o canto é expressão desta oração. Portanto, é necessário cuidar da adequada formação litúrgica e espiritual de todos que atuam nesse campo pastoral da Igreja (cantores, instrumentistas, compositores, poeta, letristas e técnicos). É fundamental que tenham conhecimento da natureza eclesial da liturgia, do seu sentido teológico e espiritual, das orientações quanto à forma e sentido de cada rito. E que não seja apenas uma formação teórica e técnica, mas que proporcione uma verdadeira experiência do celebrar.

Ao lado da música litúrgica estão também outros elementos altamente simbólicos e significativos para o alimento da fé da comunidade. É importante se ter consciência da própria sacramentalidade de toda ação litúrgica. Às ações de uma assembleia correspondem as ações simbólicas, a composição simbólica do espaço, dos objetos, das vestes litúrgicas. A harmonia desses elementos contribui e muito para que o mistério possa ser revelado com nobre simplicidade. No que diz respeito à música, temos no Brasil um repertório variado, consistente e acessível, incluindo o Hinário Litúrgico da CNBB. É necessário se visitar esse arcabouço, como já o dissemos no começo de nosso artigo. 
Certamente a pandemia deixou nossas assembleias vazias, e o corpo eclesial celebrativo não pôde se reunir para fazer sua ação de graças de louvor ao Pai, pelo Filho, no Espírito, através da principal celebração litúrgica: a Eucaristia. É louvável que muitos ministros do canto e da música litúrgica estão se esmerando para que seja assegurada minimamente possível uma música de qualidade nas celebrações que são transmitidas via redes sociais ou aplicativos virtuais. Vimos muitos grupos, cantores e instrumentistas se empenhando nisso. Mas também notamos muito empobrecimento nessa área. Contudo, isso não é fruto apenas da pandemia ou do distanciamento social que nos trouxe a pandemia. Antes mesmo isso já era percebido.

Circulou entre nós vídeos em que músicos discutiam com o padre que estava presidindo a celebração, pois este padre queria pedir músicas para serem cantadas de improviso ali na hora da celebração. Outro ainda em plena transmissão rejeitava o repertório escolhido pelo cantor, criticando o conteúdo da letra. Pelo menos foram os dois exemplos que nos vieram à mente, mas o leitor certamente deve ter visto outros vídeos desses circulando. Diante desses dois exemplos questionamos o modelo operativo que ocupa a música litúrgica ou a música nos contextos dos templos e dos nossos dias. Não se trata de simples casuísmo. Não é cantar por cantar ou cantar para simplesmente preencher um espaço vazio. A música litúrgica não se destina a este fim. Ela é fruto de um conjunto ritual e esse propósito deve ser obedecido, seguido e vivido por quem se propõe a trilhar nesse ministério.

\section{Pequenas assembleias reunidas}

Por outro, lado nos perguntamos: quem é esta pequena assembleia reunida para celebrar o Dia do Senhor e fazer sua transmissão a tantos quantos se destinam a assisti-la? Não imaginemos que os cantores e instrumentistas presentes nessas 
transmissões deixam de ser assembleia pelo simples fato de estarem exercendo uma função ministerial. Certamente trata-se de uma assembleia reduzida, dois ou três, um grupo de familiares talvez, que se reuniu para animar essas transmissões.

Verdadeiro serviço exerceram esses que, doando seus talentos, puderam fazer com que o povo tivesse acesso a essas celebrações via redes sociais. Embora não seja o ideal: o virtual, o distante, mas também nos entristece o fato de que não estávamos preparados para isso. Nossos irmãos evangélicos, neopentecostais ou protestantes estão há anos-luz à nossa frente quando o assunto é transmissão midiática. De certa forma, eles já vêm fazendo isso há muito tempo com assembleias cheias e comunicação imediata que satisfaz e atende bem a seu público.

Logicamente não é o desejado pela Igreja: celebrações sem assembleias, isto é, sem povo. "Onde estiverem dois ou três reunidos, eu estarei no meio deles", assim disse Jesus. As celebrações só têm sentido se ali estiver reunido o povo de Deus. Um é quem preside esta assembleia, os demais servem a esta mesma assembleia, cada um fazendo somente aquilo que lhe compete, embora sendo membros desta mesma assembleia. A função ministerial da assembleia é ser assembleia.

Analisando mais profundamente essas celebrações sob o ponto de vista de sua ministerialidade, o mais estranho que nos pareceu é que alguns presidentes interagem com o usuário da mídia social como se ali este usuário estivesse presente, esquecendo-se que minimamente havia em torno dele uma assembleia fisicamente presente, isto é, o pequeno grupo de cantores e instrumentistas que se propôs a cantar aquela celebração.

\section{Das liturgias à dura realidade social}

Há de se levar em conta também o conteúdo textual das músicas que se oferecem nessas celebrações. Há muito conteúdo textual nessas músicas que não possui sequer perspectivas sérias 
dos conceitos de Igreja do Concílio Vaticano II. Além disso, nota-se certo hibridismo textual, por exemplo numa música veiculada o texto afirma que a comunhão é "para nos preservar em ti”. Muito mais que isso, o ato de comungar sacramentalmente sob as espécies do pão e do vinho é para sermos um com o outro. "E quando recebermos o corpo e o sangue dele oferecidos, o Espírito faça de nós um só corpo e um só espírito. Fazei de nós um só corpo e um só espírito", afirmamos no meio da oração eucarística. Note que não se trata de conceitos antropológicos, mas são conceitos teológicos que têm consequências no cotidiano das pessoas de fé. Não se trata de uma preservação no sentido de conservação, como se o nosso corpo fosse uma espécie de museu que preserva a comunhão sacramental recebida. Como não se tem a Teologia como base para a construção da letra, fica difícil se apropriar dos conceitos básicos da fé quando se refere a letras de música que cantam questões sacramentais. Sobre este tema requer uma catequese aprofundada e outro artigo careceria para refletirmos o assunto.

Outra coisa ainda é dizer que para cada tipo de música se percebe uma interpretação diferente por parte dos cantores, como se estivessem num show, cheios de expressões faciais e corporais que nada condizem com a letra. Aliás, digamos que muito mais que sonoridade vocal, alguns cantores investem em extrair das assembleias apenas as mãos balançando ao alto, pulos e palmas. Isso é infantilizar as assembleias e empobrecer o sentido gestual-musical que se requer quando se canta com a assembleia a fim de lhe assegurar a afinação e a participação. $O$ que está em jogo quando se canta é a voz. Dela se origina o sentido da participação pelo sentido vocal requerido pela reforma litúrgica pós-conciliar: que a voz acompanhe com a mente aquilo que se faz enquanto rito. Deixemos a tarefa saltitante e eufórica para os programas de auditório e para os cantores populares em geral quando estes estão em seus shows. 
Quando também estão em jogo nessas transmissões a imagem, o que importa mesmo é mostrar como eles são capazes de fazer superproduções, vídeos magníficos com câmeras maravilhosas de última geração e tecnologia de vanguarda. Muitos desses clipes rolam indiscriminadamente nas redes sociais e estão arquivadas no Youtube para se mostrar o quanto eles são artistas, aproveitando-se do elemento religioso e da fé a fim de mostrarem seus talentos, inclusive muitos padres embarcaram nessa. Sem contar que o ostensório com a hóstia consagrada virou objeto de verdadeiro marketing apelativo que toca o lado extrassensorial das pessoas, evocando nelas emoções múltiplas.

Carece resgatar o sentido verdadeiro da nobre simplicidade, expressão utilizada pela reforma litúrgica. A música litúrgica, o espaço litúrgico, as vestes litúrgicas e todas as ações rituais precisam beber desta fonte. Eis o critério para o qual deveríamos convergir. Mas me parece que há tempos algumas celebrações no Brasil querem mais competir com celebrações de basílicas romanas do que viver a simplicidade de assembleias populares com rostos sofridos e marcados pela dor, pelo luto, pela miséria e pela falta de esperança com as quais marcaram o povo brasileiro nesse tempo de pandemia, sobretudo ao serem atingidas por um governo que tratou a saúde pública como um caso privado ou particular, isto é, cada um que se salve a si mesmo com as condições que possui.

\section{Textos musicais que assegurem aprofundar a linguagem ritual}

Em certa ocasião, Márcio Antônio de Almeida, especialista em musicologia disse numa de suas exposições que importa olharmos para o modelo operativo do canto litúrgico, o que é próprio de cada canto. Variam nesses modelos os cantos de Abertura e Comunhão, com suas flexibilidades próprias. A regra da oração vale para a regra do que se crê, e vice-versa. No conteúdo desses dois tipos de cantos deve prevalecer aquilo que 
a Igreja possui em sua mais antiga tradição da fé, isto é, o conteúdo da fé explícito nesses cantos deve condizer com o conteúdo da fé propostos pelos ritos celebrativos. É dos ritos que se originam as letras, a poesia, o texto.

Notamos que certos conteúdos expressados em muitas letras de cantos estão mais para um apelo midiático, isto é, para seduzir pessoas, e isto deve ser imediato, ali, na hora, caso contrário não surte efeito. De certa forma, o imediatismo é a linguagem do momento: as mensagens devem ser instantâneas pelos aparelhos e pelas mídias, o ouvinte ou o leitor do outro lado do mundo deve me responder imediatamente; eu fico monitorando se ele recebeu, leu ou não respondeu a mensagem enviada. Isso vai tornando os indivíduos seres sensíveis, pois tudo está muito ligado à flor da pele. Não consigo esperar mais, a paciência não é mais um adjetivo aliado às tecnologias. A cultura do superficial dita as regras do tempo atual, e nada se é aprofundado. Perguntamos: vale a pena ficar mesmo na superfície? Por que o Mistério profundo é a nossa dúvida? Por que não se vai atrás do essencial e se abandona o que é passageiro, transitório? Mesmo que não queiramos, as celebrações via redes sociais ou midiáticas caíram nisso. Como escapar dessa crise do não aprofundamento das questões mistéricas? Há caminhos de volta?

Para Márcio ainda precisamos formar uma geração de músicos cantores e instrumentistas a partir de uma educação para o rito e para a linguagem ritual pela qual se vivencie o rito como substrato de nossas produções litúrgico-musicais. A isso nós chamamos de mistagogia, com a qual começamos nosso artigo ao relembrarmos como se apreende a experiência vital que passa pelos ritos e pela linguagem litúrgica. Esse jeito de aprender e vivenciar a fé é o patamar para avançarmos no bem celebrar, isto é, celebramos porque sabemos o que celebramos, para quem celebramos e aonde celebramos. Isso abrange muitos elementos da celebração, e a música litúrgica é um deles. Por 
exemplo: quando o assunto é letra poética, há mais preocupação com a poesia do que com os significados dos ritos para a vida daquela assembleia litúrgica. Márcio ainda recordou que é preciso conhecer bem o que se celebra para poder devolver às nossas assembleias o genuíno conceito de ter pelo menos o direito de evocar suas tradições e costumes, e isso pode ser conduzido com devidos critérios pela música litúrgica.

\section{Para concluir}

O cenário atual, a música litúrgica, o contexto da pandemia e pós-pandemia, os aparatos tecnológicos devem, acima de tudo, nos apontar caminhos bíblico-teológico-litúrgicos na busca de acertar com critérios para se poder celebrar bem a liturgia com cantos que condigam com a fé da Igreja, com elementos simbólico-gestuais que sejam significativos para a vida do povo celebrante, com sinais que sejam verdadeiros e não subjetivos, seja virtual ou presencialmente.

\section{Referências Bibliográficas}

SACROSANCTUM CONCILIUM. Constituição sobre a Sagrada Liturgia. São Paulo: Paulinas, 2010, 10a ed.

DOCUMENTOS DA IGREJA. Documentos sobre a música litúrgica (19032003). São Paulo: Paulus, 2005.

CNBB. A Música Litúrgica no Brasil. Um subsídio para quantos se ocupam da música litúrgica na Igreja de Deus que está no Brasil. São Paulo: Paulus, 2009, 5aed. (Doc. Estudos da CNBB n.79).

CNBB. Orientações pastorais para as mídias católicas: imprensa, rádio, TV e novas mídias. Brasília: Ed. CNBB, 2018 (Doc. Estudos CNBB n.111).

UNIVERSA LAUS. Grupo internacional de estudos sobre música litúrgica. Documento de 1980.

CASEL, Odo. O mistério do culto no cristianismo. São Paulo: Loyola, 2009.

BUYST, Ione. Participar da liturgia. São Paulo: Paulinas, 2012.

CARPANEDO, Penha. In: Revista de Liturgia. Cantando a uma só voz. São Paulo: Apostolado Litúrgico, n.251, set-out. 2015. 